\title{
Research on International Protection Modes of Individual Privacy inWe-media Era
}

\author{
Hou Denghua, Zhao Yingxue \\ School of Humanities and Social Sciences, University of Science and Technology Beijing, Beijing, \\ China, 10008
}

The People's Procuratorate ofBeijing Huairou District, Beijing, China, 101400

denghua003@16.com

Keywords: we-media,human flesh search, privacy rights, legal regulation

\begin{abstract}
The rights of people to express their views have been fully respectedin we-media age. However, with the development of the internet technology, the violation of the right of privacy has a tendency to spread. This paper will expound the international protection modes of individual privacy in we-media era to provide some references for the relevantresearchers.
\end{abstract}

\section{Individual Privacy in We-media Era}

The arrival of we-media age has become an important force to promote social progress, but it also increases the number of network infringement cases, where the user's network privacy infringement has become more and more popular. The violation of individual privacy has become a hot issue in the world. The main international organizations and countries have set up a system to protect the right of privacy of the network. Because the network privacy is mainly carried by the personal information or personal data, it is usually the protection of the right of network privacy in the protection of personal information or data. The EU and its member states adopt a unified approach to regulation. The EU has formulated the "personal data protection directive" and "electronic communications data protection directive", as a guide to the formulation of relevant legislation of Member States. The majority of its member states have formulated the unified legislation for their own.

Right of privacy, which is enjoyed by the natural person, is the right that private information, private life and private space cannot be illegally instructed, known, collected and used. It is cornerstone of the survival of people in real life. The protection of personal privacy is based on the economic foundation, the development of science and technology will always appear all kinds of new things, people in social interaction will be influenced by the new things, so as to affect the social relations, the protection of privacy with the progress of science and technology, from paper to the network presents a different form of expression. But whether it is a violation of the traditional right of privacy or Internet era with the help of human flesh search element of privacy infringement, from the legal nature of the difference is not much difference, but is the means of infringement, as well as the media and ways of communication are different.

Origin of legal protection of the right to privacy in the United States, 1980 jurist Samuel D. Warren and Louis - D - Brandeis in the Harvard Law Review, a famous "on the right to privacy," a text, put forward due to the technological progress and the urban newspaper has been a violation of the personal and civic life sacred territory, and pointed out clearly that individuals have a right not to be disturbed. The legal protection of the right of privacy has become an important issue for the scholars of all countries. At this stage of our country, the right of privacy is the nature of privacy. It is the personal information, private activity and the private sphere that the natural person enjoys. 


\section{Foreign Protection Modes of Individual Privacy in We-media Era}

\section{American Protection Mode}

Dispersive Legislation:The legal protection of privacy in the United States is a gradual and dispersive legislation, and has not formed a complete system for the protection of the right to privacy. Now as the country of the world's most advanced network technology, the enactment of the numerous relates to the protection of network privacy laws and policies. Comprehensive privacy protection legislation is enacted in 1974, the privacy act, which provides for the collection and disclosure of personal information in the United States federal government agencies, and the provisions shall not be used without the consent of the parties to use any information on the parties, that is prohibited unauthorized personal records leaked. In April 21of 2000, which came into force in, the federal law on Internet privacy, the law on the protection of children's online privacy act, must be obtained before the collection of personal information for children under 13 years of age, and allows their parents to retain the right to stop their use in the future.

Industry Self-regulation:American high tech companies have not wanted the government to intervene, to solve the problems that exist at present. Lines Broad, vision Air, Click Double, ecustomers.com and other 26 companies and other organizations, including a total of more than 90 members of the organization, the Privacy Alliance Online (OPA) was established, the alliance aims to ask the company to tell the user what is being collected data belonging to the scope of the individual can handle, and allows them to choose from. The United States government believes that the self-regulatory mechanism (including corporate behavior standards, private "certification system" as well as alternative dispute resolution mechanism) with the government's law enforcement and protection, can effectively achieve the purpose of privacy protection. To this end, the United States government has maintained a dialogue with the business community and consumer groups, to encourage more privacy protection, the use of self-disciplined privacy policy. In addition, another major means of the United States industry self-regulation is the implementation of network privacy certification program, which is a private enterprise committed to the protection of the right to privacy in the network form. The program requires that a site that is licensed to post a privacy certification mark on the site must comply with its rules of conduct, and subject to various forms of supervision and management. This certification mark has the significance of commercial reputation, easy to consumers to identify those who comply with the rules of the site, but also to the network service providers to show their compliance with the rules of the situation.

Judicial Pecedents:Adapted to the legal system of the United States, the judicial precedents established some important principles of the right to privacy protection. Nissan Bourke Motor Email Company in the case of the protection of the privacy rights of the general principle: "prior to know the company policycan be regarded as a reasonable expectation of privacy, and the access to the site does not constitute intercepted."

Through the protection of privacy rights in the United States, we know that the collection, storage, use and disclosure of all kinds of private information have very strict procedures. Whether it is for other individuals, organizations or even government agencies, there are strict procedural norms in order to achieve the purpose of protecting the privacy of individuals.

\section{European Union's Protection Mode}

There is a common understanding on the principle of the proper use of information, which is mainly reflected in the establishment of the obligation and responsibility to establish the personal information, maintaining the transparency, special protection for sensitive data, and the realization of the right. These basic principles constitute the method system of protecting personal information in Europe, which is reflected in the laws and conventions of the European Union. In the European Union, the guiding principle of "personal data protection and the free movement of such data" (referred to as "the EU Data Protection Directive") is also reflected in the European Union in 1995.

In order to fulfill the data processing required for data processing, in order to protect data from the legal obligations of the parties, in order to protect the data processing required for data processing, in order to fulfill the data processing required to fulfill the legal obligations of data processing, the data processing is needed to protect data. Basic rights and interests are more 
important than this. In addition, the Directive requires Member States to take appropriate technical and organizational measures to protect personal data from accidental or illegal destruction, to prevent accidental loss of data and unauthorized modification of data, disclosure or access. The EU Directive on the right to privacy as a basic human right to protect, and for the collection of personal information provided by the strict procedures to limit the risk of personal privacy disclosure.

In many countries, such as Germany, the federal personal data protection act, as the German federal court to achieve the function of the protection of personal information. Other countries, such as Britain, France, Italy, Russia, Australia, Canada, Japan, Korea and other countries have also developed the special privacy protection law to protect the personal data.

\section{Hong Kong and Taiwan Protection Modes of Individual Privacy in We-media Era}

\section{Hong Kong Mode}

The most detailed provisions on the protection of the privacy of citizens in Hong Kong are the Hong Kong's personal data (Privacy) Ordinance, which came into force in December 20, 1996. The regulations mainly related to the collection of personal information, methods, ways of use and safety protection measures and other provisions, such as the fourth provisions of the Ordinance: data users may not make any violation of the principle of security data or in violation of any of these principles, but if the act or act (as the case may be) is subject to the provisions of this Ordinance shall be made or permitted to do or, then an exception." The basic principles of the collection of information and the personal information of the user's obligation are combined. In addition, the establishment of the Hong Kong Office of the Privacy Commissioner for personal data as the executive authorities is given a wide range of investigation and enforcement powers to protect personal privacy security.

\section{Taiwan Mode}

The protection of the right of privacy in the Taiwan area of China mainly includes the "personal information protection act" (computer processing of personal data protection act) in 1995. According to the provisions of Article 7 of the law: "official on the collection of personal data or computer processing nonspecific purpose, and meet one of the following circumstances shall not: within the scope of the provisions of the act duties necessary; the parties agreed in writing; the right of the parties no likelihood of infringement." Limit the authority of the state organs to collect personal information. The eighteenth article provides the conditions for the non-official organization to collect or deal with the personal data: the party's written consent; the relationship between the party's written consent; the party's rights and interests of the parties, and the party's rights and interests are not infringed, the party's rights and interests are not infringed upon; the public information and harmless to the major stakeholders; for academic research is necessary and harmful to the interests of the parties and for the public and the non-official organs of the violation of the provisions of this ordinance.

\section{Tendency of International Protection of Individual Privacy in We-media Era}

\section{Stress Business Field}

We-media age provides great conveniencefor the development of economic and trade, particularly for the promotion of cross-border trade, cross-border transactions, the significance of e-commerce has been rapid development. E-commerce enterprises in the business process will get a large number of user information, including personal information, including the information of other enterprises, which contains a huge business value. In addition, from the entire electricity suppliers in the control of personal information (including legal person) point of view, these information also has a huge national strategic value. Electricity suppliers and related organizations, such as other enterprises, logistics companies, financial institutions, insurance companies and other complex relationships, it is likely to need to share this information, and thus bring information security issues. All countries in the world attach great importance to the protection of personal information and privacy in the electronic commerce environment. 


\section{Regulate Data Application}

In the development of cross-border data flow rules, all countries control to transfer data to carry out the necessary restrictions as the transfer of data is easy to cause information leakageto the right people to bring damage. The EU's personal data protection directive, the data were classified, which is the so-called sensitive information in principle is prohibited, and to perform public affairs or the exercise of public power and the third parties to disclose data, the purpose of the legitimate interests of third parties based on data management and receiving data can also disclose data, but this interest cannot exceed the interests of the data subject, freedom and basic rights.

\section{Protect Special Group}

In the process of the universal countries pay attention to protect the network user's personal information and privacy data, many countries began to pay attention to the privacy protection of special populations. It includes the minors, employees, consumers and patients and other specific groups. For example, the United States not only has a special "Privacy Act", but also for minors to develop a "child online privacy protection act". In short, the world and the international organizations in the personal information and privacy data protection are showing a trend of further refinement, which is also the protection level of performance. In we-media age, we shouldimprove the legislation of personal data protection, to achieve the protection of personal privacy.

\section{References}

[1] Hou Denghua, The Protection of Personal Right of Privacy in Internet, J., Law Science Magazine, 9(2014)72-79.

[2]Zhang Jing, The Protection of Privacy Under We Media Environment-Discuss About Article 36 of "Tort Liability Act", D., Inner Mongolia University, 2014.

[3] Deng He, On the Protection of Individual Privacy in Public Places, J., Journal of Shanxi Normal University (SocialScienceEdition), 2 (2006)34-36. 